\title{
ROS induced inflammation is key driver of afb I induced hepatocellular carcinoma
}

Keywords: hepatocellular carcinoma, aflatoxin b1, reactive oxygen species, cancer related inflammation

Abbreviations: HCC, hepatocellular carcinoma; AFB1, aflatoxin B1; CRI, cancer related inflammation; NFkB, nuclear factor kappa b; TNF, tumor necrosis factor; COX-2, cyclooxygenase-2; iNOS, inducible nitric oxide synthase; DED, death effectors domain; TRADD TNF, associated death domain; cFLIP, cellular fasassocciated death domain like interleukin-1- $\beta$ converting enzyme inhibitory protein

\section{Opinion}

Reactive oxygen species and inflammation are known to promote tumor progression. ${ }^{1}$ ROS causes genomic instability and necrotic cell death $^{2}$ this in turn, may induce production of pro-inflammatory factors resulting into neoplastic progression in case of many cancers. ${ }^{3,4}$ It has been observed that AFB1 also induces necrotic cell deaths in the liver to drive hepatocarcinogenesis. ${ }^{4}$ Thereby, it is hypothesized that AFB1 induced HCC might involve ROS led, inflammatory cascades during hepatocarcinogenesis (Figure).

Investigation on involvement of inflammatory cascade in AFB1 induced HCC development

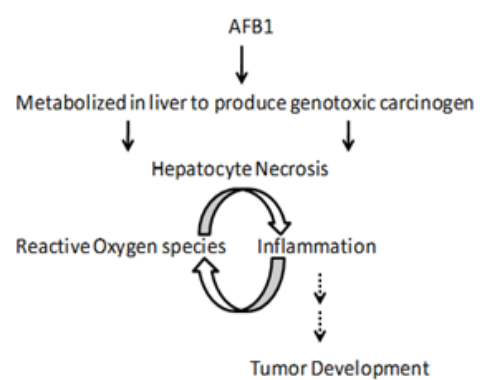

ROS and inflammation together drive progression of AFB1 induced carcinogenesis

Figure ROS and inflammation drive progression of $A F B I$ induced carcinogensis.

Based on the findings during recent past, it is assumed that cancer related inflammation (CRI) could be considered as another hallmark of cancers ${ }^{5}$ because this event is found to be shared by almost all types of cancers. ${ }^{6}$ Among inflammatory factors of the CRI; IL- $1 \alpha$, IL-1 $\beta$ and TNF $\alpha$ are considered to be of much importance. This is because; they implicate NFKB dependent expression of many cell proliferative factors. ${ }^{7}$ IL- $1 \alpha$ activates the nearby inflammatory cells and thereby, provokes NFkB dependent production of a battery of tumorigenic factors. ${ }^{1,7}$ In addition, TNF $\alpha$ signaling also results into translocation of $\mathrm{NF \kappa B}$ into the nucleus, which in turn induces expression of certain inflammation supportive factors like; Bcl2, COX-2, iNOS and IL-1 $\beta$, which are known to support tumor growth also. ${ }^{7}$

TNF $\alpha$ signaling is evident to be critically implicated in tumor progression. ${ }^{8}$ This involves competitive interaction of TRADD vs

\author{
Volume 4 Issue I - 2018
}

Brajesh Kumar Maurya
Department of Zoology, Uttar Pradesh State University, India

Correspondence: Brajesh Kumar Maurya, HOD, Department of Zoology, Govt. PG College Obra Sonebhadra-231219 Uttar Pradesh, India,Tel 9450061618, Email bkmbhu@gmail.com

Received: January 29, 2018 | Published: February 12, 2018

cFLIP with TNF-R cytosolic domain ${ }^{9,10}$ 2010. Several mutations in TRADD and cFLIP in breast cancer, cervical cancer and HCC cell lines have been reported to enhance the binding of cFLIP to DED domain of TNF $\alpha-R$ and thereby promoting cell survival over induction of apoptosis in these cells. ${ }^{10}$ Thus, altered ratio of TRADD vs CFLIP is considered to be critical during TNF $\alpha$ signaling induced tumorigenic progression.

In this context, TNF $\alpha$-activated nuclear NFאB (p65) translocation into nucleus and maintenance of $\mathrm{Bcl} 2$ constitute a mechanism of driving the cells in proliferation pathway. ${ }^{7}$ In addition, Expression of NFKB dependent genes like COX-2 and iNOS are also found to be critically involved in inflammation induced tumor development. However, whether this mechanism is involved in AFB1 induced HCC development remains unexplored.

\section{Acknowledgements}

None.

\section{Conflict of interest}

Author declares that there is no conflict of interest.

\section{References}

1. Sakurai T, He G, Matsuzawa A, et al. Hepatocyte necrosis induced by oxidative stress and IL- $1 \alpha$ release mediate carcinogen-induced compensatory proliferation and liver tumorigenesis. Cancer cell. 2008;14(2):156-165.

2. Kamata H, Honda SI, Maeda S, et al. Reactive oxygen species promote TNF $\alpha$-induced death and sustained JNK activation by inhibiting MAP kinase phosphatases. Cell. 2005;120(5):649-661.

3. Maeda T, Hobbs RM, Merghoub T, et al. Role of the proto-oncogene Pokemon in cellular transformation and ARF repression. Nature. 2005;433(7023):278-285.

4. Singh KB, Maurya BK, Trigun SK. Activation of oxidative stress and inflammatory factors could account for histopathological progression of aflatoxin-B1 induced hepatocarcinogenesis in rat. Mol Cell Biochem. 2015;401(1-2):185-196.

5. Colotta F, Allavena P, Sica A, et al. Cancer-related inflammation, the seventh hallmark of cancer: links to genetic instability. Carcinogenesis. 2009;30(7):1073-1081. 
6. Mantovani A, Allavena P, Sica A, et al. Cancer-related inflammation. Nature. 2008;454(7203):436-444.

7. Berasain C, Castillo J, Perugorria MJ, et al. Inflammation and liver cancer Annals of the New York Academy of Sciences. 2009;1155(1):206-221.

8. Kwon HJ, Won YS, Suh HW, et al. Vitamin D3 upregulated protein 1 suppresses TNF- $\alpha$-induced NF $\kappa$ B activation in hepatocarcinogenesis. $J$ Immunol. 2010;185(7):3980-3989.
9. Safa AR, Day TW, Wu CH. Cellular FLICE-like inhibitory protein (C-FLIP): a novel target for cancer therapy. Curr Cancer Drug Targets. 2008;8(1):37-46.

10. Bagnoli M, Canevari S, Mezzanzanica D. Cellular FLICE-inhibitory protein (c-FLIP) signalling: a key regulator of receptor-mediated apoptosis in physiologic context and in cancer. Int J Biochem Cell Biol. 2010;42(2):210-213. 